\title{
A new direction in PWR simplification
}

\author{
Nicolaas M. Bonhomme* \\ Le Ponteil, 05310 Champcella, France
}

Received: 27 March 2020 / Received in final form: 29 October 2020 / Accepted: 18 December 2020

\begin{abstract}
A new approach to PWR simplification is presented, in which a compact Reactor Coolant System (RCS) configuration is introduced, particularly suited for a power level in the range of 600 MWe. Customary PWR primary system components are eliminated to achieve this RCS simplification. For example, RCS pressure control through a "self-pressurization" mode, with core exit at saturation temperature with less than $1 \%$ steam, allows elimination of a pressurizer. Also, mechanical control rods are replaced by reactivity control using negative moderator void and temperature coefficient together with variable speed primary pumps, and with an upgrade in the safety boration function. Decay heat removal in shutdown conditions is realized through the secondary side rather than through primary side equipment. The compact RCS can be installed in a small volume, high-pressure containment. The containment is divided into two leak-tight zones separated by a partition plate. Safety equipment installed in one of the two zones will be protected against adverse ambient conditions from leaks or breaks in the other zone. The partition facilitates management of coolant inventory within the RCS and the containment following RCS leaks or breaks. In particular, the safety injection system as commonly known, consisting of accumulators and multiple stages of injection pumps can be discarded and replaced by gravity-driven flooding tanks. Space available around major RCS components is adequate to avoid compromising accessibility during maintenance or in-service inspection operations. In addition, the two-zone, high-pressure containment provides extra margins in severe accident mitigation. Finally, the proposed containment has a much smaller size than customary large dry containments in PWR practice and it can be anticipated that Nuclear Island building size will similarly be reduced.
\end{abstract}

\section{Introduction}

Nuclear power plant designs which are implemented in current construction projects or which can be envisaged in projects for the near future are practically all of the Light Water Reactor (LWR) type (the only exceptions are fast reactor projects in China and India and heavy water reactors planned in Argentina and India).

The "near future" timeframe mentioned above corresponds to the period in which a substantial transition to a low-carbon electricity infrastructure will have to be achieved in order to meet the objectives of the UN framework convention on climate change for the years 2020 until 2050 [1,2].

The established LWR technology for near future projects relies principally on two types of LWR design: on the one hand the "Generation III or III+" designs of large LWRs (1000 MWe or above), of which several projects are already under construction and on the other hand the new LWR approach exemplified by the SMR, "Small Modular

\footnotetext{
* e-mail: paronicamani@outlook.fr
}

Reactors". The SMR design proposals are all of smaller size, from 50 to $350 \mathrm{MWe}$, and some are proposed to be grouped together on a single site to provide a total of around 600 MWe [3].

The object of this paper, as can be surmised from its title, is to present a third approach, which is based on the premise that it is possible to develop a very much simplified PWR configuration with a power level in the range of 600 MWe.

The guiding principles used in defining this simplified PWR are:

- the focus of the simplification effort is on the Reactor Coolant System (RCS) and on the safety-grade equipment inside containment. This might be at the expense of somewhat more elaborate requirements on the secondary side systems. However, in this type of tradeoff, the secondary side option can offer more design flexibility and greater accessibility for maintenance, repair, or for post-accident emergency operations.

- a small volume, high-pressure containment can accommodate a compact Reactor Coolant System arrangement and will provide high backpressure which reduces requirements on emergency core cooling systems, 


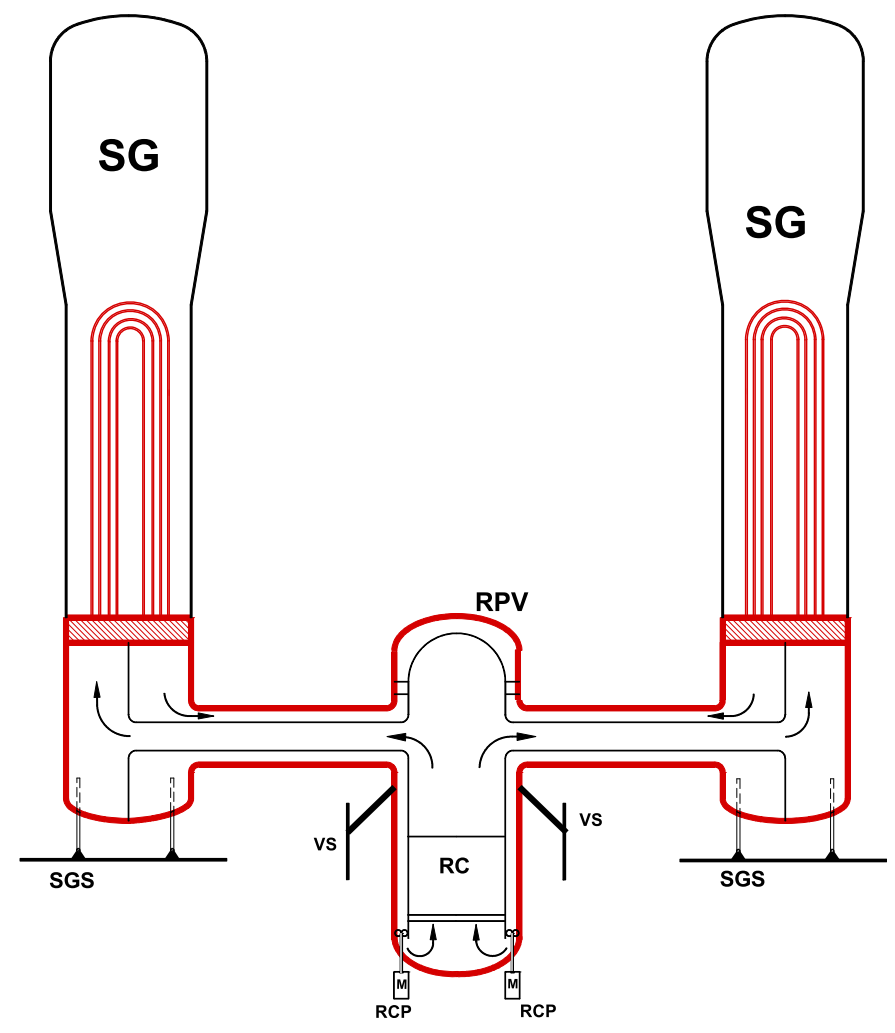

Fig. 1. A compact Reactor Coolant System (RCS). With a "selfpressurization" concept there is no pressurizer, the reactor core exit flow is saturated water with minimal steam quality (less than $1 \%$ ), RCS design pressure is reduced to $\sim 125 \mathrm{bar}$, and RCS hot leg is at 110 bar, saturation temperature $318^{\circ} \mathrm{C}$. Variable speed Reactor Coolant Pumps (RCP) are mounted at the Reactor Pressure Vessel (RPV) bottom circumference. Trip of the RCP, together with negative moderator void coefficient, ensures rapid negative reactivity insertion due to voiding at core exit, assisted by a safety boration to hot and/or cold shutdown condition. There is no need for mechanical control rods. The items indicated in the figure are: RPV, reactor pressure vessel; SG, steam generator; RC, reactor core; VS, RPV support; RCP, reactor coolant pumps; SGS, SG support.

- even with the smaller volume containment the implementation of maintenance, repair, in-service inspection, and periodic testing operations must remain achievable and close to current LWR practice.

The first step in simplification is achieved by a compact arrangement of the Reactor Coolant Pressure Boundary (RCPB) which will reduce the likelihood of loss of coolant accidents, thereby approaching the similar advantages as with a single integral Reactor Pressure Vessel (RPV) used in many SMR designs. This compact RCS configuration is presented in Section 2 and Figure 1.

Additional simplification is achieved by a number of design options which either will completely eliminate traditional PWR components (e.g. no need for a pressurizer by use of a "self-pressurization" concept, as explained in Section 3, and no mechanical control rods by use of moderator control through negative reactivity feedback, upgraded safety boration, and variable speed pumps, see Sect. 4) or will replace them by functions added to the secondary side (e.g. residual heat removal through the steam generators, Sect. 6) and finally by a new small volume, high pressure containment concept incorporating two different containment zones, as explained in Section 5 and illustrated in Figures 2 and 3.

Section 7 discusses the treatment of Severe Accidents and Section 8 provides a synthesis of the new PWR configuration. The final Section 9 presents a conclusion.

\section{Reactor coolant pressure boundary (RCBP)}

In SMR designs of the PWR type the favored approach is to arrange all major components of the reactor coolant system into a single integrated reactor pressure vessel (RPV), in which all components of a typical PWR Reactor Coolant System are contained within the RPV. The compilation of SMR designs issued by the International Atomic Energy Agency [3], identifies 19 land-based water cooled SMR's, of which 15 are PWRs. With only two exceptions, these are all using the single integrated RPV concept.

The maximum power of the proposed SMRs employing the single integrated RPV concept is 350 MWe, with a thermal power not larger than 1000 MWth. Increasing power above this range is not feasible without abandoning the current industrial practice in fuel characteristics and in steam generator (SG) design. Such an integrated PWR concept at a power of 1000 MWe has been developed, but has required a high power density core design (15-40\% higher than current LWRs, using silicide fuel), and compact "micro-channel-type" heat exchangers coupled with external steam drums to replace traditional steam generator designs $[4,5]$.

For a plant power in the range of $600 \mathrm{MWe} / 1800$ MWth, and with a prerequisite to rely on well-established experience in existing fuel supply infrastructure and main component designs, it will be necessary to abandon the "single integrated RPV concept". In a conventional type of PWR, the Reactor Coolant System comprises a number of main components, including a Reactor Pressure Vessel (RPV), Reactor Coolant Pumps (RCPs), Steam Generators (SGs), and a pressurizer. The SGs and RCPs are arranged into two or more coolant loops connected to the centrally located RPV, and the pressurizer is connected to a hot leg piping section in one of the coolant loops. The interconnected assembly of RPV, RCPs, SGs, pressurizer and coolant piping is positioned in a cylindrical or a spherical containment building. In a large evolutionary PWR, this containment can have a size of $40 \mathrm{~m}$ or more.

However, a simpler and more compact primary system configuration can be found and can provide advantages compared to existing PWR practice.

Figure 1 shows a configuration incorporating a Reactor Pressure Vessel connected to two Steam Generators via a pair of double piping connections. Coolant flow-paths are indicated by arrows in this illustration. The Reactor Coolant Pumps (RCPs) are mounted on the bottom head of the RPV. The Reactor Coolant Pressure Boundary is 


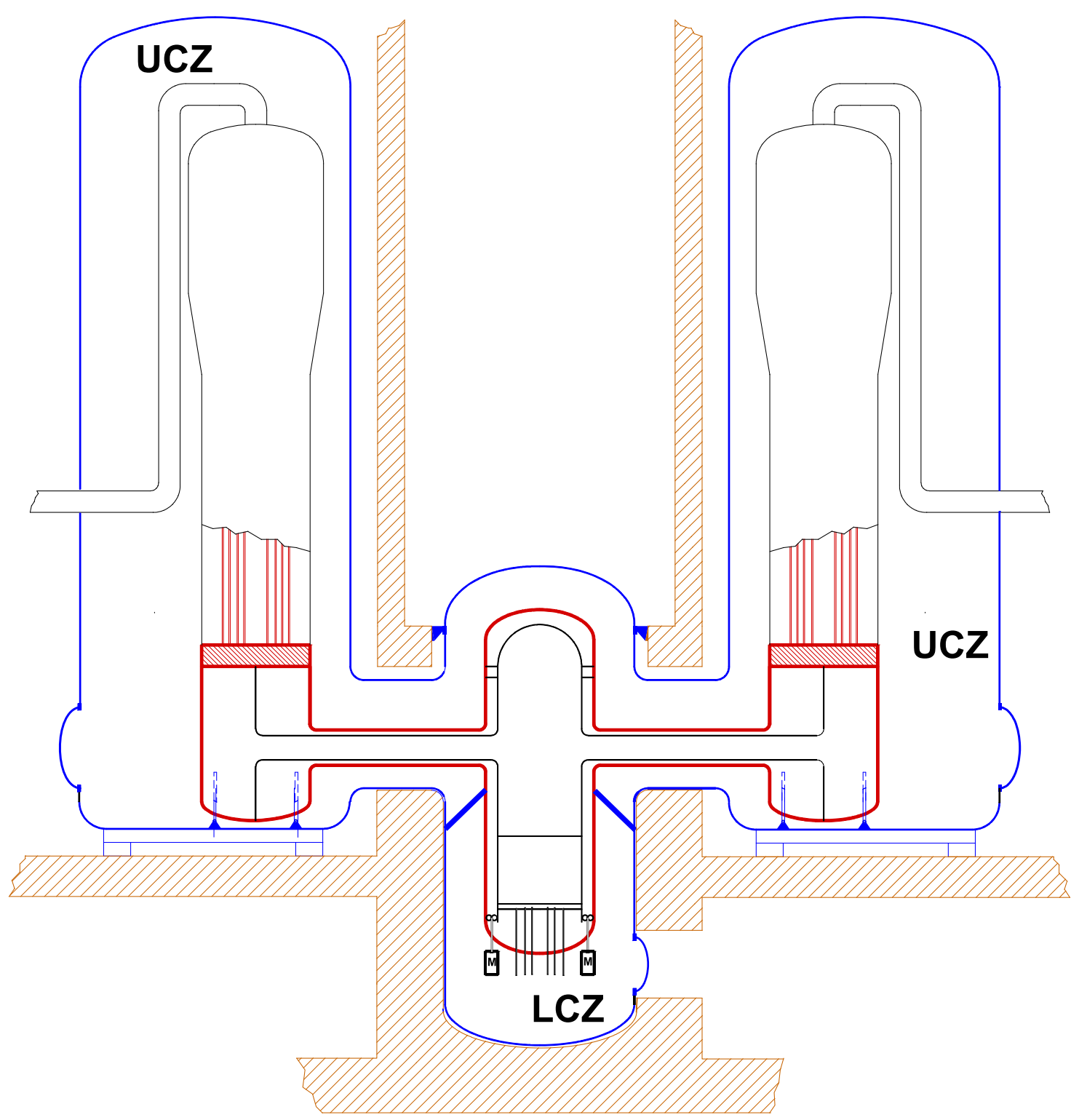

Fig. 2. Two-zone, small volume, high pressure containment. The containment is partitioned into two separate leak tight zones: LCZ the Lower Containment Zone, consisting of the reactor cavity below the RPV, and containing the RCP's mounted on the RPV bottom, and other equipment, not shown (e.g. shielding, instrumentation). Free volume of the LCZ is approx. 230 cubic meters. UCZ the Upper Containment Zone, comprising the region surrounding the upper part of the RPV and the two Steam Generator (SG) compartments. Free volume of the UCZ is at least 4500 cubic meters. The free volume in the lower part of the UCZ, that is, below the level of the RCS main piping connections, is approx. 700 cubic meters. Maximum pressure for both LCZ and UCZ is close to 20 bars. Four containment access openings include the containment dome above the RPV, and access ports for the LCZ (reactor cavity), and for the SG compartments.

limited to the RPV, the two Steam Generator channel heads, the two sections of straight piping connecting RPV and SG's, the SG heat exchanger tubes, and finally various sections of smaller diameter piping of safety systems or of auxiliary systems that connect to the Reactor Coolant System (these are not shown in Fig. 1).

The support structure for the RPV will be a "fixed point" type, restraining movement of the RPV in all six degrees of movement, while the SG supports will have to admit movement of the SGs in an axial direction, to allow for thermal expansion of the connecting double piping sections between the cold and the hot operating conditions. The vertical, inverted U-tube SG's can be of a design known from operating PWR experience, as in two-loop 600 MWe PWR units, or also in three loop 900 MWe units. The two SG's, of about 350 metric tonnes each, will be at approximately $10 \mathrm{~m}$ distance from the RPV. Their support structure will therefore be closely similar to current practice in PWR plant design. An illustration of this support structure is included in Figure 2. 


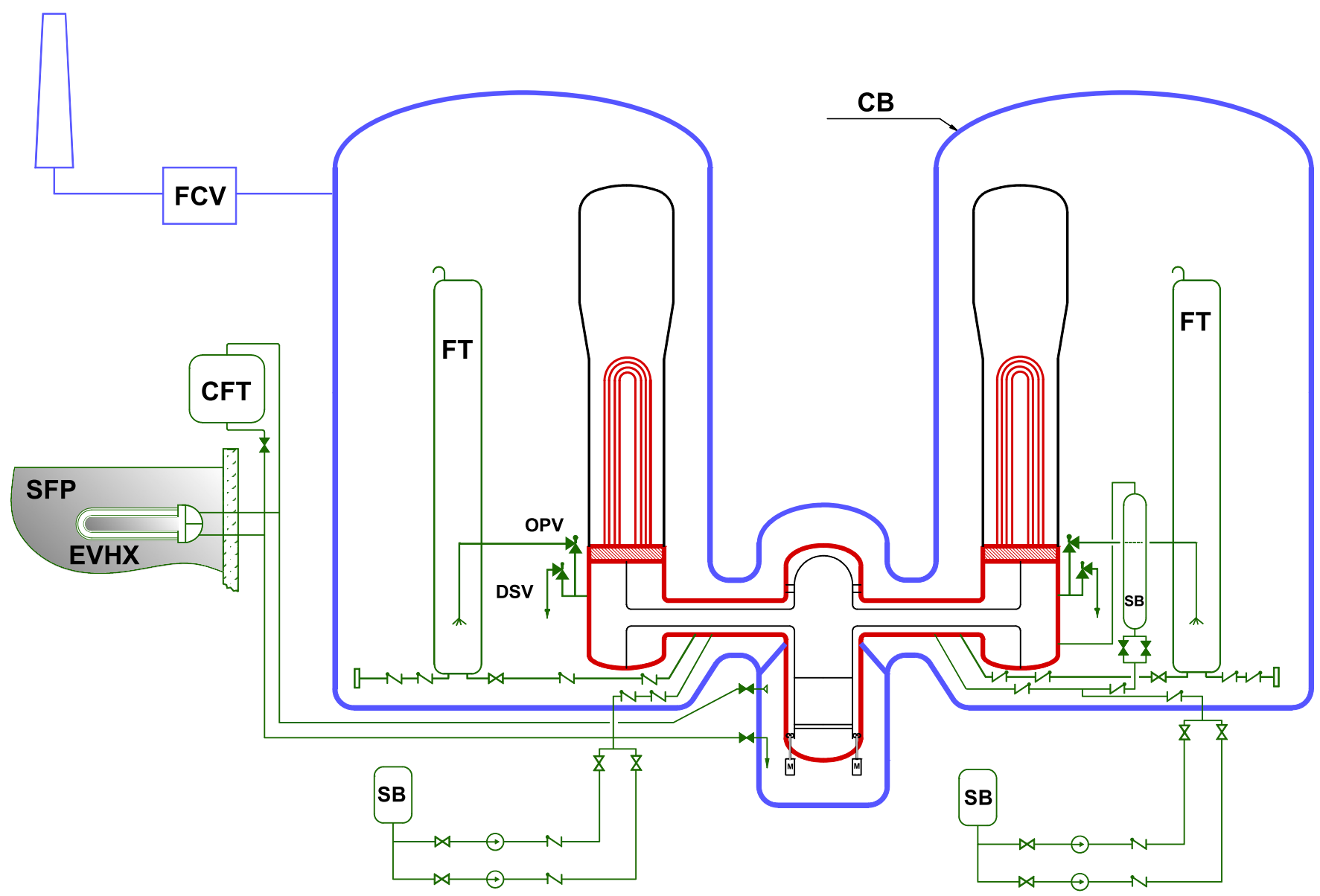

Fig. 3. Primary side safety systems. Essentially all primary side safety systems are shown in this figure, the only exceptions being: isolation valves in non-safety grade systems, hydrogen igniters/recombiners, and various instrumentation and surveillance equipment. The items indicated in the figure are: CB, containment boundary; FCV, filtered containment vent; SFP, spent fuel pool; CFT, cavity flooding tank; SB, safety boration tanks; EVHX, ex-vessel heat exchanger; FT, flooding tanks; DSV, depressurization system valves; $\mathrm{OPV}$, overpressure protection valves.

But since in the present case only one piping connection is provided to each SG, the stability of the SG support is no longer ensured in the event of a guillotine rupture of this piping connection. If protection against such a double-ended guillotine break (DEGB) were to be required an axial restraint limiting outward axial displacement of the SGs would ensure that the loss of SG support stability could be precluded (such a restraint is not shown in Fig. 2).

In addition, this axial restraint can serve to limit the size of the break opening of a circumferential guillotine rupture in one of the two piping sections. For a restraint gap of fewer than $1.5 \mathrm{~cm}$, the equivalent diameter of such a limited size break will be less than $300 \mathrm{~mm}$ and the resulting blowdown thrust forces will not be sufficient to provoke pipe whip in the main coolant piping.

As an alternative, the "Leak before Break" (LBB) concept [6-8] would allow avoiding the provision of SG and piping supports and restraints designed to mitigate the dynamic effects of a piping rupture. Further discussion of such considerations will be presented in Section 5 below, as part of the emergency core cooling system presentation.
The inner piping sections in each of the two double piping connections shown in Figure 1 provide a flow path from the core exit to the hot leg side SG channel heads. This inner piping will have to accommodate differential thermal expansion due to temperature differences between hot and cold legs and due to possible differences in material properties. The inner piping structural design, including the connections to the SG channel head partition plate and to the RPV internals, must allow this type of differential displacement without excessive stresses or thermal fatigue, and with zero or negligible bypass leakage between hot and cold flows during power operation. A small amount of bypass flow from hot to cold leg can be accepted in specific operating conditions (e.g. in cold shutdown or in longerterm post-accident situations). Also, it is advantageous to include a capability to dismantle and remove the inner piping sections during the required 10-year in-service inspection shutdowns. This capability would facilitate access for inspection of both the inner piping sections and of the inside surface of the RCPB outer piping envelope. The dismantling operations would not be required during a normal refueling schedule. 


\section{Self-pressurization}

In a PWR operating with core outlet in a saturated condition, with core exit steam quality slightly above but close to zero, a stable primary loop operating condition can be maintained without the need for a pressurizer. This "self-pressurization" mode of operation has been known since the early years of LWR development [9].

The first (and only, so far) PWR type reactor operated on this design principle was the power plant of the third nuclear-powered cargo ship "Otto Hahn". After a maiden voyage completed on October 11, 1968, the Otto Hahn nuclear propulsion plant was deactivated in 1979, having traveled a total of 650.000 nautical miles in reliable operation without technical incidents [10,11].

Two of the SMR designs described in the IAEA booklet referenced above also incorporate the self-pressurization option, the CAREM-25 project (CNEA, Argentina) and the IMR design (MHI, Japan). Both have selected an integral PWR concept with self-pressurization and natural circulation in the primary coolant loop. In the Otto Hahn reactor plant, a forced circulation mode of the selfpressurization concept has been employed and this option is also selected in the proposal of this paper. The use of forced circulation, combined with a very minimum core exit steam quality can ensure that the occurrence of twophase flow instabilities is avoided. Appendix A provides additional information regarding applicable stability conditions.

The compact RCPB as described in Section 2 is well suited for the adoption of a self-pressurization mode of operation. For a primary pressure of 110 bar at the core outlet, the hot leg temperature will be $318^{\circ} \mathrm{C}$ which is close to currently practiced PWR hot leg temperatures. Core outlet steam quality should be only slightly positive, ensuring hot leg two-phase flow conditions in the "bubbly flow" regime, and a range of acceptable values would be between $x=0.001$ and $x=0.01$. At part load operation, between hot shutdown and 100\% power, these hot leg pressure, temperature and steam quality conditions are to be maintained constant at $110 \mathrm{bar}, 318^{\circ} \mathrm{C}$. At $100 \%$ power, for a primary coolant mass flow also in the same range as in standard PWR practice, the cold leg temperature would be $294^{\circ} \mathrm{C}$ and the subcooling at core entry would be $24^{\circ} \mathrm{C}$. With these primary system temperature and flow characteristics vertical U-tube type Steam Generators as commonly installed in PWR practice can be used. The motivation for selection of a hot leg temperature close to existing PWR practice stems from the need to ensure a physical and chemical environment in which existing operating experience provides confidence that unexpected component damage or deterioration are avoided. This is of particular importance with regard to stress corrosion cracking in PWR primary water systems [12].

One consequence of the lower operating pressure is its impact on the critical heat flux (CHF), which at 110 bar pressure will be different from the value at a 155 bar pressure for a standard PWR design. Inspection of the CHF lookup tables from reference [13] shows that for a mass flowrate of $4000 \mathrm{~kg} / \mathrm{m}^{2} \mathrm{~s}$ and for all values of quality below $x=0.05$, the critical heat flux at 110 bar is larger than at 155 bar. And the critical heat flux at 110 bar and steam quality $x=0.01$ is larger than the critical flux in a PWR at 155 bar, core outlet temperature $318^{\circ}$ (quality $x=-0.0093)$.

It follows that the thermal hydraulic conditions in the proposed self-pressurized PWR can be substantially similar to those in PWR designs known from operating plants. The principal difference is obviously the lower operating pressure, the core exit at slightly above saturation, and an average moderator density somewhat lower than in a PWR.

The fuel temperature profile will also be substantially similar to operating PWR experience if the same type of fuel assembly as in operating PWR's is used (e.g. a standard $17 \times 17$ fuel assembly), together with the same average linear power.

The lower operating pressure in the primary system will lead to a lower design pressure (e.g. 125 bar as compared with approximately 175 bar in current PWR practice) and will allow a reduction in RCPB wall thickness as compared with standard PWR experience. This factor has also played a role in the selection of the type of reactor unit for the "Otto Hahn" (Neumann, [10], page 95).

Forced circulation of reactor coolant is provided by Reactor Coolant Pumps mounted on the circumference of the bottom head of the RPV. These are variable speed pumps for reasons explained in the next sections. The location at the RPV bottom head is proposed in order to ensure that the RCP can remain operational in case of an RCS leak or break, as in a LOCA accident, and can assist in providing forced circulation for core cooling also with low coolant inventory in the cold legs and in the RPV downcomer (see the discussion on containment and emergency core cooling in Sect. 5). The objective to maximize the NPSH margin in LOCA is the principal motivation for mounting the RCPs on the RPV bottom head.

For a two loop, 1800 MWth reactor core a suitable option is to provide eight bottom-mounted RCP units, with a four-train electric power supply, two RCP being assigned to each one of the four trains. The pump design will be similar to the bottom mounted recirculation pumps in European BWR plants and in the ABWR, but will have to be adapted to the larger pressure drop in a PWR-type primary loop (the eight internal recirculation pumps in the Gundremmingen BWRs together deliver almost 70.000 cubic meter per hour, which is close to the flow requirement for a two-loop 1800 MWth PWR).

Safety and relief valves, which in PWR practice are normally mounted on the pressurizer, can be located on the hot or the cold SG channel heads, or on the RPV head. They will need to be qualified for the release of steam, water, and two-phase fluid.

\section{Reactivity control}

A combination of mechanical control rods and of boric acid concentration in the primary coolant is the preferred method of reactivity control in moderate to large size PWR 
power plants. Small size power plants such as reactors for marine propulsion generally use only mechanical control rods and no boron.

The new simplified PWR proposal uses a design without control rods but with boron as a means to allow reactivity adjustments during normal plant operation and to assist reactor shutdown by safety boration. In normal plant operation the boron concentration is used to compensate core reactivity changes induced by fuel depletion and by reactor power variations. This type of procedure is the same as is practiced in standard PWR operations. It is generally implemented through a Chemical and Volume Control System (CVCS), which also allows maintaining reactor coolant chemistry within technical specification limits and ensures control of reactor coolant inventory.

The elimination of mechanical control rods in the new simplified PWR implies that another means must be found to ensure a fast reactor shutdown. For a reactor operating in a self-pressurization mode a possible alternative ensuring fast reactor shutdown is to rely on a trip of the RCP, which results in a rapid expansion of steam voiding in the upper part of the core and a negative reactivity insertion if the moderator void coefficient is negative. This first phase of initial rapid power reduction will provide time for startup of fast boration pumps which will ensure continued power reduction down to a hot shutdown condition. Additional details included in Appendix B present a simplified mathematical model that can illustrate the basic principle of this method of fast reactor shutdown.

In standard PWR design practice the moderator temperature coefficient is required to be equal to or less than zero in all critical core conditions and in particular at the beginning of a refueling cycle, when the highest boron concentrations in a critical core condition are encountered. For the no-rods case, this requirement must be tightened to ensure that the moderator temperature coefficient will always be negative and below a suitable limit value, established on the basis of results from comprehensive transient analyses. The negative moderator temperature coefficient implies a positive density coefficient which ensures that steam voiding in the upper regions of the core following the pump trip can induce a reactor shutdown.

Control rods in PWRs are not used exclusively for rapid emergency shutdown. They are also required to participate in reactor power adjustments occurring in normal operation, together with boron concentration variations.

Without control rods in the proposed self-pressurized PWR such power control can be accomplished by relying on reactivity adjustments resulting from moderator density and temperature feedbacks, on boron concentration adjustments, and also on additional control possibilities provided by the variable speed RCP's.

One possible RCP speed control strategy is based on maintaining a constant power-to-flow ratio over the power operating range from nominal $100 \%$ power down to the minimum operating power. This leads to a RCS temperature distribution which remains substantially constant during load variations, thereby ensuring that reactivity variations due to the moderator density coefficient are minimized. Boron concentration adjustments are necessary in order to offset reactivity variations due to changes in fuel temperature and in Xenon concentration resulting from the reactor power variations. In this control strategy the primary system temperature fluctuations and therefore also mechanical constraints on primary system components can be very much reduced. The same is true for the CVCS charging and letdown line temperatures. Fuel burnup towards the end of a refueling cycle (EOC) will lead to a reduced boron concentration, with as a consequence that the time to achieve a required boron dilution objective will be increased. This has a negative impact on the fast return to power capability at EOC.

In another control strategy the RCP speed is maintained constant, equal to its nominal value at $100 \%$ power, during all full and part load operating conditions. If core outlet pressure and steam quality are also maintained constant the cold leg temperature will increase when core power is reduced. Core averaged moderator density is then reduced in part-load operation. Compared to the case of a constant power-to-flow ratio the primary side temperature fluctuations will be increased but the boron/dilution requirements are reduced and fast return to power capability will be available during a more extended part of the refueling cycle.

Other RCP speed control modes, intermediate between the two described here, are possible to achieve intermediate performance objectives.

Finally, in large LWR reactor cores control rods are used to preclude power distribution oscillations resulting from Xenon distribution transients. This requirement is not needed for a smaller core size and the size limit above which Xenon oscillations can become a concern is about 600 MWe/1800 MWth (other factors apart from only core size can come into play, as, for example, the core height to diameter ratio). An example of results of preliminary calculations for the reactor design of 640 MWe discussed in the next paragraph (the PIUS project) can be found in reference [14]. These results are presented for various core heights between 2.5 and $3.8 \mathrm{~m}$. No oscillations are apparent for a $2.5 \mathrm{~m}$ height, but for the higher core heights oscillations are increasingly obvious.

At this point it is of interest to note that one particular PWR design without mechanical control rods is known: this is the PIUS project from the Swedish company ABB Atom [15]. The PIUS design incorporates a strongly negative moderator temperature coefficient and a special configuration of primary coolant flow paths in which a trip of the reactor coolant pumps induces an automatic boration of core coolant by inflow from a large pool of high boron content water. The USNRC report SECY-93-092 [16] describes USNRC staff pre-application reviews of four different reactor designs, including the PIUS design. Pages 15-16 of SECY-93-092 provide the results of the NRC staff review of the PIUS Reactivity Control System and, in particular, the issue raised by the USNRC General Design Criterion number 26, which requires that two independent reactor trip systems be provided, one of which should use 
control rods. The staff recommendation, as reported on page 16 , has concluded that a design without control rods may be acceptable and has required that sufficient additional information must be provided to justify an "equivalent level of safety".

The importance of a negative moderator void coefficient (or positive moderator density coefficient) for a core without rods will require a greater emphasis on a requirement that at each first startup following refueling a measurement of the moderator density coefficient be performed. The measured value should conform to the predicted value established in the core design analyses for the refueling campaign. On the other hand, the periodic testing required to verify acceptable rod drop times, as currently practiced for rodded cores, will obviously be abandoned.

For a "no rods" design it is still necessary to consider accident scenarios of the type ATWT (Anticipated Transients Without Trip), but the postulated failure of all control rods to insert into the reactor core must be replaced by consideration of failure of safety actions implemented to ensure reactor protection (e.g. failure of RCP trip, failure of one diverse means of safety boration, failure to start emergency feedwater supply to $\mathrm{SGs})$.

Without mechanical control rods, several transient or accident analyses commonly required in PWR safety analysis will no longer be pertinent while for other analyses the safety margins will be improved. For example, an inadvertent control rod or rod bank withdrawal, a spurious rod drop, or a rod ejection accident are all excluded in a core without rods.

Also, without control rods the analyses of steam line breaks (SLB) need not consider the presence of a stuck rod. One of the cases of SLB analyses for PWR's is a case where one of the control rods has remained stuck outside the core, all other rods are inserted, and the reactor is initially in a hot zero power condition. With such an initial condition the large SLB leads to a rapid cooldown of the RCS which introduces positive reactivity and as a consequence a return to power in the core (the assumption of hot zero power maximizes the core cooldown rate). A stuck rod will then cause a local power peak, concentrated in the assembly with the stuck rod and the Departure from Nucleate Boilng (DNB) margin will be minimum in this particular location. The stuck rod condition is not possible in a core without control rods, the excessive local power peaks in SLB cases are precluded and the power distribution will be more uniform.

Accident management in the case of a Steam Generator Tube Rupture (SGTR) accident is very similar to known practice for PWR's. However, an important difference will be the reduced flowrate from the ruptured SG tube, due to the lower pressure in the RCS.

Other transients or accidents to be considered in safety analyses (blackout or loss of external power, inadvertent boron dilution, excess power demand from SG, and others) also are closely comparable to the PWR cases, with the exception of Loss of Coolant Accidents (LOCA), which are discussed in the next Section.

\section{Containment and emergency core cooling}

It is known (see e.g. [17]) that emergency core cooling systems can be simplified when a small volume, higher pressure containment concept is adopted and use is made of the higher containment backpressure developing during blowdown in a loss of coolant accident (LOCA). However, such a small volume containment is not well suited for large evolutionary type PWRs. The very much restricted space available around major components in such a configuration would significantly complicate accessibility for maintenance, repair, and in-service inspection operations. For SMR-type designs, the adoption of a small volume, highpressure containment option can be more attractive and has indeed been selected in some cases (e.g. for IRIS and IMR, see [3]).

Figure 2 shows a new small volume, high-pressure containment concept [18], adapted for the RCPB configuration of Figure 1. In this concept, the containment volume is divided into two zones separated by a leak-tight partition plate in the form of a conical RPV supporting skirt positioned below the main coolant nozzles. The largest diameter of the cylindrical containment sections containing the SG will be around $10 \mathrm{~m}$. This is approximately four times smaller than the steel containment diameters in large evolutionary PWRs, and as a result, the design pressure can be around 20 bar with a wall thickness substantially the same as in the larger size containments. The option shown in Figure 2 depicts a steel containment shell but alternatives with parts of the containment envelope in a prestressed concrete construction are also possible.

Moderate to large break LOCA accidents can be excluded from the lower containment zone, below the partition plate. In this lower region only very small breaks or leaks from instrument lines or from RCP flanges, need be considered (note that radiation shielding, neutron flux measurements, and RPV level instrumentation, to be arranged in the annular space between RPV and the containment envelope, are not shown in Fig. 2). A design requirement for the instrumentation lines and for the RCP will be that potential leaks or breaks be restricted to less than a defined equivalent piping diameter, for example, an equivalent diameter of at most $20 \mathrm{~mm}$. The mass flow rate from a break of such diameter will not be larger than $15 \mathrm{~kg} /$ $\mathrm{s}$. The leak is detected by increasing pressure in the lower containment zone so that automatic protection system actions are initiated. The flowrate is small enough to allow it to be compensated by makeup from safety boration systems. Reactor trip and plant cooldown will return the plant to below $20 \mathrm{bar} / 212^{\circ} \mathrm{C}$ in approximately $20 \mathrm{~min}$, and the breakflow will gradually decrease while pressure in the lower containment zone increases close to 20 bar.

For a LOCA in the upper containment zone the provision of a partition serves three important functions (see Figs. 2 and 3 for illustration):

- hazardous ambient conditions resulting from the blowdown of high-pressure steam and water in the upper containment zone will not propagate to the lower zone. Therefore equipment in the lower zone, such as the RCP, the RPV level measurement and the neutron flux 
instrumentation located in this region, will remain available for accident mitigation and post-accident monitoring. In particular, the RCP operating at reduced speed and powered by emergency electric power supplies can be relied upon to ensure forced circulation and to permit continued heat removal through the SG's. This is of interest especially in cases where incondensable gases (e.g. hydrogen) could present a risk of blocking natural circulation through the SG tube bundle.

- the containment volume requirement corresponding to a given minimum backpressure at end of blowdown can be allocated entirely to the upper containment zone. As a result, the space available around the SG's, the upper $\mathrm{RPV}$ head, and the primary coolant piping is increased relative to a situation without a partition. For a backpressure of the order of 20 bar and an RCS volume of 300 cubic meters, the containment volume would have to be at least of the order of 4500 cubic meters (expansion of 225 tonnes of saturated water at 110 bar results in a volume expansion by a factor around 17 or 20 , depending on whether one assumes isentropic or isenthalpic conditions). In a configuration as depicted in Figure 2, the space available within the upper containment region would then be closely similar to the space allocation in current practice for major equipment rooms of PWR containments. Access openings, indicated in Figure 2, can be provided to facilitate in-service inspection and maintenance operations.

- at the end of blowdown, the pressure within containment and within the RCS will have reached an equilibrium level in the order of 20 bar. Loss of inventory from the RCS is however still possible by draining of liquid phase water into containment. The loss of inventory can be neutralized either by the flooding of the lower regions of the upper containment up to a level above the break location or by ensuring that a flow path is available from these lower regions through the cold leg piping towards the RPV downcomer. Flooding tanks, located in each of the two SG compartments (see Fig. 3), can deliver the required amount of flooding water. With the RPV support skirt blocking flow towards the lower RPV cavity the volume in the lower part of the upper containment zone up to the top of the RCS piping is limited to less than 700 cubic meters (estimated from Fig. 2). A flooding tank capacity of $350 \mathrm{~m}^{3}$ volume in each of the SG compartments is therefore sufficient to ensure long term heat removal following LOCA.

- for cold leg breaks the flooding level above the top of RCS piping is sufficient to cover any possible break location. Inventory loss from the RCS will, therefore, be stopped when RCS pressure has decreased to below containment pressure. After this point in the accident sequence, a continued SG secondary side cooling will lead to steam condensing on the primary side within the SG tube bundle. RCS pressure can decrease to below containment pressure and RCS inventory will then recover due to makeup from the flooding tanks and also by return flow through the break. The cold leg volumes and the RPV downcomer will have been refilled with water from the flooding tanks, thereby enabling continued operation of the RCP and forced circulation cooling of the core.

- for hot leg breaks the maximum break size is significantly smaller than for the cold leg breaks since no main coolant piping pressure boundary is present on the hot side of the RCS. Auxiliary piping connected to the hot leg side need not be more than $100 \mathrm{~mm}$ diameter (for example discharge lines to safety valves). Contrary to the cold leg case, the hot leg break locations may be situated above a flooding level at the top of the RCS piping. Therefore the flooding tanks are to be equipped with refill line connections so that a flow path is available from the lower regions of the upper containment towards the flooding tanks and from there to RCS cold legs. At the end of blowdown, the RCS pressure will be in equilibrium with containment pressure and flooding tanks will have started injecting towards the cold leg volumes and will refill the RPV downcomer. RCP operation can continue to provide forced circulation to the core and the SGs. However, a part of the flow will be diverted through the hot leg break towards the containment volume. The water volume collected in containment will return via flooding tank refill lines to the cold leg. This flow path represents a bypass of the steam generators. Nevertheless, the break size (less than $100 \mathrm{~mm}$ diameter) is small compared with the SG tube bundle flow cross-section (which is more than the equivalent of $2 \mathrm{~m}^{2}$ ) and this bypass is unlikely to jeopardize the SG decay heat removal function.

With these characteristics, emergency core cooling will be ensured by forced circulation using the RCPs, by heat removal through the SGs, and by RCS inventory recovery through the flooding tanks (but for small breaks or leaks the forced circulation of RCPs is not needed since RCS natural circulation is sufficient).

Injection from the flooding tanks is driven by the static head of the tank water level, which can be about $20 \mathrm{~m}$ above the break location and will start injecting when the RCS pressure decreases to less than 2 bar above the containment pressure. Head losses in injection lines connecting the flooding lines to the cold legs of the RCS can be designed to well below the available static head : flow at $5 \mathrm{~m} / \mathrm{s}$ through a DN250 piping of $15 \mathrm{~m}$ length, including two check valves, delivers $190 \mathrm{~kg} / \mathrm{s}$ injection with a head loss of $10 \mathrm{~m}$, and at $20 \mathrm{~m}$ head this flowrate increases to $265 \mathrm{~kg} / \mathrm{s}$. A low head safety injection pump for large evolutionary plants $(3800$ MWth or larger) typically supplies around $150 \mathrm{~kg} / \mathrm{s}$, while the injection from accumulators in these plants will start at 45 bar (EPR, AP1000), or at 25 bar (Konvoi). Furthermore, the small volume, high pressure containment design will cause breakflow to diminish to negligible values when RCS and containment pressure are equalized at 20 bar. In comparison, the breakflow at 20 bar in a DEGB for a large volume containment (less than 7 bar design pressure) can still be in the range of thousands of $\mathrm{kg} / \mathrm{s}$ or more, depending on water/moisture content in the discharge flow.

For moderate size breaks, for example, a break in one of the injection lines from the flooding tanks (DN $250 \mathrm{~mm}$ or 
less), decrease of RCS pressure to below containment pressure will take more time. For these types of breaks the continued forced circulation using RCP at reduced speed will assist in core cooling while an accelerated RCS cooling via the SG's through SG relief valves will advance the moment where RCS pressure decreases below containment pressure, flow through the break is reversed, and the injection from flooding tanks is initiated.

The Safety Injection System as used in many PWRs of the current design (comprising redundant trains of accumulators, and of low head and high head safety injection pumps) is reduced to only the flooding tanks and associated piping and valves. A completed and convincing safety case will evidently require detailed analyses using qualified computer codes (RELAP, CATHARE, or others) and for the full range of possible break sizes. Such analyses are not available at present. However, the capacities of emergency cooling capacities from flooding tanks, RCP operation at reduced speed, and SG heat removal can be designed sufficiently powerful to compare favorably with those of known safety injection systems in current PWR's.

When a sufficient containment design pressure is chosen there will be no need for containment heat removal. The safety boration system, necessarily provided as noted in Section 4, will be started and will contribute to maintaining adequate boron concentration, but with sufficient boron content in the flooding tanks (e.g. $2500 \mathrm{ppm}$ boric acid) its operation need not be critical.

It has been noted in Section 2 that the size of a circumferential rupture in the main coolant piping can be limited by an axial restraint limiting movement of the SG on the broken loop. Such a restraint would also serve to ensure the stability of the SG support structure. Nevertheless, the double-ended guillotine break (DEGB) would still have to be considered as the maximum size LOCA since leaks or ruptures from longitudinal or axial cracks cannot be excluded even if they would not jeopardize SG support stability.

The LBB methodology has been used increasingly in nuclear power plant applications as an alternate means of mitigating the dynamic effects of pipe rupture, as mentioned in the references cited in Section 2 [6-8]. In the present case, the adoption of the LBB approach can benefit from existing LWR experience. With the straightforward compact RCPB geometry, featuring only two straight main coolant piping sections, the established LBB analysis methods can be applied. Leak detection will be facilitated by the small volume containment, even if the lower RCS operating pressure will reduce somewhat the leak-rate through postulated cracks in the LBB analyses.

With LBB there no longer is a requirement to mitigate dynamic effects of piping ruptures and the axial SG restraint referred to in Section 2 and above in the present Section 5 will not be necessary (and such a restraint is not shown in Fig. 2). Nevertheless, the design of the emergency core cooling (RCP at reduced speed, flooding tanks, containment backpressure) will have to consider the DEGB break, postulated as a conservative upper-bounding analysis to show that no excessive core damage can occur.

\section{Residual heat removal and secondary side systems}

The new approach to PWR simplification includes the elimination of a dedicated primary side Residual Heat Removal System (RHRS) and its replacement by heat removal through the SG under all operating conditions, with the exception of only the refueling shutdown. As a consequence, it must be shown that heat transfer from the reactor core to the $\mathrm{SG}$ secondary side is possible in all such conditions and also that heat transfer from the SG secondary side to an ultimate heat sink is ensured at all times. Without a primary side RHRS, the complete failure of all SG heat removal capability would lead to unacceptable core damage and possibly core melt if such capability is not recovered. ${ }^{1}$

The variable speed RCPs are able to ensure forced circulation residual heat removal through the steam generators for all operating conditions between hot and cold shutdown. Below an SG pressure and temperature of around 5 bars and $150^{\circ} \mathrm{C}$, this will require a liquid phase heat removal mode from the SG to an ultimate heat sink. Therefore a piping connection must be arranged from the SG internal region above the tube bundle towards the auxiliary feedwater tanks and equipped with a heat exchanger to cool this return flow before it enters the feedwater tank.

An internal cover positioned inside the RPV separates the hot leg flow path at core exit from the cold leg return flow towards RCP suction. The internal cover will be removed only in a refueling shutdown to allow access for replacement of fuel assemblies. This operation can be performed after RPV upper head removal and filling of the refueling canal. The RCP operation is to be stopped at this time and residual heat removal is then ensured by the spent fuel cooling systems. In the sequence of operations during a refueling shutdown the removal of the internal cover is placed at a similar point in time as the removal of RPV upper internals in operating PWR's and involves similar handling precautions.

As in most standard PWR designs, natural circulation within the primary coolant system remains also available for heat removal through the SG's and for RCS conditions from hot shutdown down to cold shutdown, provided SG secondary side heat removal remains operative.

Proper functioning of Secondary Side Heat Removal deserves greater emphasis in the new configuration presented here since post-accident long term decay heat removal relies on heat transfer through at least one of two Steam Generators. The "feed and bleed" procedure used in plants with a more elaborate safety injection system on the primary side is here only available for a short period, up to reflooding of RCS inventory through the flooding tanks. Heat removal through the SGs would normally rely on auxiliary feed supply through motor-driven and/or turbine-driven auxiliary feedwater pumps, together with

\footnotetext{
1 A similar approach with residual heat removal through the steam generators has been adopted in the «IRIS» SMR design proposal [3].
} 
atmospheric pressure relief valves, safety valves, and also the liquid phase SG heat removal mode mentioned above. Probabilistic risk analyses will have to determine whether reliability goals and in particular Core Damage Frequency targets can be satisfied or whether an additional diverse or passive means of SG heat removal would be required (e.g. redundant air-cooled safety condensers connected to the steam and feed lines of each SG). This will depend on the reliability of offsite electric power supplies and therefore also very much on the utility network environment in which the power plant would be installed.

\section{Severe accidents}

Nuclear safety regulations have evolved towards explicit consideration of requirements aimed at the prevention and mitigation of severe accidents [19-21].

In the proposed small volume containment option these requirements remain relevant. Several features either already foreseen in operating plants or proposed for new PWR plants can be adopted also in the present case. For example, an automatically or manually initiated depressurization of the RCS, using dedicated pressure relief piping and valves, will serve to avert a core melt sequence at high RCS pressure. These depressurization valves are indicated as "DSV" in Figure 3. Two independent DSV valve sets are provided, one in each of the SG containment compartments. They constitute an additional redundant and independent depressurization means, parallel to the overpressure protection valves "OPV" of Figure 3 . In case of RCS overpressure transients, RCS leaks, or a small LOCA, only the OPV will be required, while the DSV are dedicated to the practical elimination of a high pressure core melt sequence. Another function already foreseen in other LWR designs is the filtered containment vent (FCV in Fig. 3) intended to preclude excessive activity release in the event of progressive over-pressurization of the containment.

In other cases, the small volume containment or other characteristics of the new configuration will necessitate adaptations or may enable alternative arrangements. As shown below, there are instances in which these could lead to a more robust safety case.

With up to eight variable speed RCP at the RPV bottom, it is possible to eliminate the risk of strong and rapid reactivity excursions due to a heterogeneous dilution event. With adequate restrictions on RCP startup sequence and on the rate of increase of RCP speed the effects of a slug of undiluted primary water being propelled into the reactor core can be significantly reduced. A slow initiation of forced circulation will permit the moderator temperature and voiding feedbacks to effectively limit the severity of the reactivity transient. As indicated earlier, in Section 4, a negative moderator temperature and a negative void coefficient are a prerequisite in the proposed PWR concept. After some time of operation at low pump speed, a homogenization of the RCS water volumes is achieved. In this manner, all the risks of rapid reactivity insertion can be eliminated.

When considering the risk of containment failure due to a hydrogen deflagration one should bear in mind that for accident scenarios in the small volume containment the combustion progression will be limited by oxygen rather than by hydrogen content. The amount of hydrogen that would consume all oxygen in a containment volume of 5000 cubic meters would be almost $190 \mathrm{~kg}$. This is considerably smaller than the amount resulting from a $\mathrm{Zr}$-water reaction involving $100 \%$ of fuel cladding, which may be three times higher. Also, the peak pressure from adiabatic isochoric combustion of an excess amount of hydrogen with all the available oxygen will not exceed the design pressure of the small volume, high-pressure containment. It remains nevertheless necessary to preclude excessive structural loads from detonation shock waves or elevated flame temperatures. Provision of igniters and/or $\mathrm{H} 2$ recombiners can ensure that containment integrity is not jeopardized. Also, a partial inerting or a partial vacuum atmosphere inside the upper containment zone can provide extra margins if needed to establish a convincing safety case. A complete inerting of the containment atmosphere, as is practiced in small containment designs with lower design pressure (e.g. BWRs with pressure suppression containment), is therefore not necessary.

In a severe accident involving a core melt with relocation towards the RPV bottom, the stabilization and retention of the core melt within the RPV can be a preferred mitigation strategy. In various published analyses such a mitigation strategy has been shown to be feasible, in particular for a reactor size of $600 \mathrm{MWe}$, or 1800 MWth [22-24]. A prerequisite for this approach is that the RPV bottom head is cooled at its external surface after the flooding of the reactor cavity to a sufficient height. In the two-zone containment described in Section 5 and shown in Figure 2 the lower RPV cavity is part of the separate lower containment zone and it will be straightforward to arrange a cavity flooding and cooling circuit, driven by natural circulation and provided with sufficient flooding water and with a condensing heat exchanger at a suitably higher elevation. This cavity flooding and cooling system will be completely independent of other accident mitigation and/ or decay heat removal systems. Common mode failures that would both lead to severe core damage with core melt relocated in the RPV bottom and, at the same time, the failure of RPV cavity flooding or cooling can, therefore, be considered as practically excluded.

It is of importance to note that provision of an ex-vessel cavity cooling system is a necessary but not a sufficient condition to ensure the feasibility of core melt retention within the RPV. Additional requirements are identified in the references cited above. They comprise design details such as the thermal insulation design for the lower RPV head, the RPV external surface characteristics and its geometry, and various other aspects. These requirements will remain applicable in the present PWR simplification proposal.

\section{Synthesis}

An overview of the different design options described in Sections $2-7$ is best explained with reference to the schematic illustration of Figure 3. 
Figure 3 shows the two-zone containment boundaries surrounding the main RCS components and the associated primary side safety systems. This includes the compact RCS as depicted already in Figure 1, the overpressure protection and depressurization valves, the safety boration, the flooding tanks and severe accidents mitigation features such as ex-vessel cooling and the filtered containment vent.

In the lower containment zone, the $\mathrm{RCP}$ will remain available in a large break LOCA to assist in core cooling. For small break LOCA, RCS leaks, or for non-LOCA events their operation is not required since natural circulation ensures core cooling and decay heat removal as long as $\mathrm{SG}$ heat removal is available. In a loss of offsite power (LOOP) or Station Blackout (SBO) scenario continued decay heat removal without reliance on emergency diesel generators can be ensured provided that secondary side cooling remains available. Either turbinedriven feedwater pumps or a closed loop steam condensing cooling circuit relying on natural circulation could be adopted to fulfill this cooling function. Shutdown margin can be maintained by opening one of two parallel valves downstream of the safety boration tank located in the upper containment.

In addition, four trains of active safety boration pumps are arranged outside containment, taking suction from two safety boration tanks. They are powered by emergency electricity supplies and provide a diverse and redundant means of attaining subcritical core conditions.

In an ATWT-type event sequence, one could postulate failure of all means of boration from the safety boration tanks of Figure 3 as well as from normal non-safety-grade chemical and volume control systems. The opening of one depressurization valve in such condition will, in a self-pressurization type PWR, immediately trigger an increased voiding within the reactor core and thus a negative reactivity insertion. If depressurization is pursued, in parallel with SG cooldown, down to equalization of pressure within the RCS and containment (at about 20 bar, $212^{\circ} \mathrm{C}$ ), the borated water content of the flooding tanks will inject into the RCS and transfer to a cold shutdown condition can be achieved.

The flooding tanks ensure the same functions as provided by the accumulators and the low head safety injection pumps in virtually all operating PWR plants. Their operation is completely "passive", requiring no valve movement other than the opening of check valves in their injection lines. The isolation valves in these lines, shown in Figure 3, are needed only in shutdown conditions and are normally locked open during operation at power. The water inventory in the tanks, borated at $2500 \mathrm{ppm}$, will ensure flooding of the upper containment zone to above the level of the double piping assemblies of the RCS.

Figure 3 shows essentially the total extent of safety systems and severe accident mitigation systems on the primary side. Items not shown are limited to various instrumentation and surveillance equipment, containment isolation valves on non-safety grade auxiliaries, RCP cooling water supplies, and the igniters or $\mathrm{H} 2$ recombiners.
The containment structure depicted in Figures 2 and 3 would preferably be housed in a Nuclear Island building which can also contain the spent fuel pool, its supporting systems for cooling and purification, and other safety grade systems and equipment. Any leakage from the containment would be collected and treated by the ventilation system in this building envelope so that no direct leakage path from the containment to the environment is possible. The building envelope will be designed against external hazards, either natural or man-made as, for example, an aircraft impact.

The size of the new two-zone containment is considerably smaller than the one for the large dry containments in common PWR practice. The maximum outside dimensions are in the range of 45 by 35 by $15 \mathrm{~m}$. The surrounding shield building for aircraft crash and natural hazards protection will also be much reduced in size relative to a shield building arrangement for a large dry containment.

In summary, the result of the PWR simplification effort can be restated:

- a compact RCS configuration, featuring an important reduction in the extent and the complexity of the RCPB, and a design pressure $25 \%$ lower than in usual PWR design practice, with state-of-the-art power maneuvering capability, although limited in power capability (less than about $600 \mathrm{MWe}$ ),

- greatly simplified primary side safety systems,

- severe accident mitigation features more than fully compatible with the latest safety and licensing requirements,

- a novel small volume, high-pressure two-zone containment ensuring accessibility for in-service inspection, maintenance or repair operations,

- the steam generator decay heat removal and cooldown systems arrangement will have to be enhanced to provide for liquid phase SG operation and to secure the necessary reliability of SG decay heat removal,

- a much-reduced containment and Nuclear Island building size.

\section{Conclusion}

The new simplified PWR arrangement presents an alternate approach to PWR development. Compared with the alternatives of either the large evolutionary plants or of the smaller size SMR proposals it can offer a viable option for a plant power in the mid-range of about 600 MWe.

Reviewing its main characteristics, as summarized at the end of the previous Section, one might imagine that any cost impact from the more elaborate secondary systems design could be more than compensated by the simplification of the RCS and of the associated safety systems, together with the possibility of a smaller size not only of the containment but also of Nuclear Island buildings. However, a demonstration of more detailed and quantitative analyses will be required to confirm such a conclusion with sufficient confidence. In addition, such further analyses will serve to 
validate in greater detail other elements of the proposed configuration, for example, the implementation of the LBB methodology, the proper sizing of safety boration, the optimal choice of containment design pressure, accessibility for maintenance and inspection, power maneuvering capability, severe accident mitigation, building size and layout details.

\section{Nomenclature}

$\begin{array}{ll}\text { ABWR } & \text { Advanced Boiling Water Reactor } \\ \text { ATWT } & \text { Anticipated Transient Without Trip } \\ \text { BOC } & \text { Beginning Of Cycle } \\ \text { BWR } & \text { Boiling Water Reactor } \\ \text { CHF } & \text { Critical Heat Flux } \\ \text { CVCS } & \text { Chemical and Volume Control System } \\ \text { DEGB } & \text { Double Ended Guillotine Break } \\ \text { DN } & \text { Nominal Diameter } \\ \text { DNB } & \text { Departure from Nucleate Boiling } \\ \text { DSV } & \text { Depressurization System Valves } \\ \text { EOC } & \text { End Of Cycle } \\ \text { FCV } & \text { Filtered Containment Vent } \\ \text { IAEA } & \text { International Atomic Energy Agency } \\ \text { IMR } & \text { Integrated Modular Reactor } \\ \text { IRIS } & \text { International Reactor Innovative and Secure } \\ \text { LBB } & \text { Leak Before Break } \\ \text { LOCA } & \text { Loss Of Coolant Accident } \\ \text { LOOP } & \text { Loss Of Offsite Power } \\ \text { LWR } & \text { Light Water Reactor } \\ \text { NPSH } & \text { Net Positive Suction Head } \\ \text { OPV } & \text { Overpressure Protection Valves } \\ \text { PIUS } & \text { Process Inherent Ultimate Safety } \\ \text { PWR } & \text { Pressurized Water Reactor } \\ \text { RCPB } & \text { Reactor coolant Pressure Boundary } \\ \text { RCS } & \text { Reactor Coolant System } \\ \text { RHRS } & \text { Residual Heat Removal System } \\ \text { RPV } & \text { Reactor Pressure Vessel } \\ \text { SBO } & \text { Station Blackout } \\ \text { SG } & \text { Steam Generator } \\ \text { SGTR } & \text { Steam Generator Tube Ruptue } \\ \text { SLB } & \text { Steam Line Break } \\ \text { SMR } & \text { Small Modular Reactor } \\ \text { USNRC } & \text { Unites States Nuclear Energy Commission } \\ & \\ \text { DOH }\end{array}$

\section{Appendix A: Two-phase flow stability conditions in a self-pressurized PWR with forced ciculation}

A self-pressurization mode of PWR operation implies a two-phase fluid condition at the core exit. With forced circulation in the RCS, the two-phase regime can be maintained in a condition most favorable for avoiding any risk of two-phase flow instabilities.

There exists an extensive literature on two-phase flow oscillation and various sources (e.g. Refs. [A-1 to A-4]) provide stability maps which delineate stability limits as a function of dimensionless parameters.
For a fixed forced circulation flow imposed by the RCP's, and with a low-quality steam condition at core exit, for example, at $x=0.01$, the important dimensionless parameters are the subcooling number Nsub, and the phase change number Npch (also called the Zuber number Nzu). For the RCS operating parameters as defined in Section 3 (110 bar core outlet pressure, 1800 MWth power, $12000 \mathrm{~kg} / \mathrm{s}$ mass flow) the values of these parameters are:

$$
N s u b=\frac{\Delta H s u b}{h g-h f} \times \frac{\rho f-\rho g}{\rho g}=1.065
$$

and

$$
N p c h=\frac{Q}{W \times(h g-h f)} \times \frac{\rho f-\rho g}{\rho g}=1.163
$$

where $\Delta H s u b$ is the subcooling enthalpy at core inlet, $\mathrm{Q}$ is the core power, $\mathrm{W}$ is the mass flow, and hg, hf, $\rho f$, and $\rho g$ are the enthalpy and density of saturated steam and water at the operating pressure.

Inspection of the stability maps in the cited references shows that with these parameter values the two-phase flow is maintained well within the stability limits. Also, it follows from the definition of Nsub and Npch that the stability conditions will not be modified as long as the power-to-flow ratio is not changed. In the discussion of reactivity control strategy in Section 4 it is noted that different strategies of variable speed RCP control are possible at part load conditions. In these various control strategies the power-to-flow ratio is either maintained constant, equal to the value at nominal full power, or is decreased in part load operation. The Nsub and Npch values are therefore allways lower than indicated above for a $100 \%$ power conditions and will not approach the stability limits, also at part load.

It must be recognized that the two-phase flow stability maps available in the literature are generally determined for specific system geometries, with different analytical and/or experimental methods and configurations (e.g. presence of a riser or chimney above the heated section, availability of buffer volumes, and others). Even if it can be expected that a forced circulation approach will allow adequate control of two-phase flow conditions, it will be necessary to confirm its applicability for the geometry of the compact RCS configuration proposed.

\section{References for Appendix A}

A-1 K. Fukuda, T. Kobori, Classification of two-phase flow instability by density wave oscillation model, J. Nucl. Sci. Technol. 16, 95-108 (1979)

A-2 George Yadigaroglu Arthur E. Bergles, An experimental and theoretical study of density-wave oscillations in two-phase flow, Report No. DSR74629-3 (HTL No. 74629-67) Engineering Projects Laboratory, Department of Mechanical Engineering Massachusetts Institute of Technology, Cambridge, Massachusetts, 1969.

A-3 L.C. Ruspini, Experimental and Numerical Investigation on Two-Phase Flow Instabilities. (Norwegian University of Science and Technology, NTNU 2013:4). 
A-4 G. Yadigaroglu, A.E. Bergles, Fundamental and higher-mode density-wave oscillations in two-phase flow, J. Heat Transf. Trans ASME 94, 189-195 (1972)

\section{Appendix B: Reactor shutdown using pump trip and safety boration in a self-pressurized PWR}

Safety-grade boration systems are already in use in operating PWR's and are used, for instance, to maintain a sufficient shutdown margin during transfer to a cold shutdown or a refueling shutdown condition. However, for an emergency reactor shutdown the startup sequence of these systems is not sufficiently rapid to en ensure safe shutdown. The safety boration pumps require at least a $5 \mathrm{~s}$ delay to initiate emergency electric power supply, followed by additional delay in fluid flow through injection line piping before the borated water will reach the reactor core. Depending on the piping layout the total delay before effective safety boration could be from 10 to $20 \mathrm{~s}$.

In the PWR design of the PIUS project rapid boration is made possible by a special fluid-dynamic design that ensures automatic ingress of borated water upon loss of forced circulation through so-called density locks. Such a rapid boration is initiated by a trip of the reactor coolant pumps [13].

In a self-pressurized PWR the trip of the RCP provides another means of rapid negative reactivity introduction, accomplished by the negative reactivity insertion following increased voiding in the upper core regions. A precondition for this is that a sufficiently strong the moderator density coefficient can be guaranteed.

This mode of reactor shutdown is illustrated by considering a simplified mathematical model based on the following assumptions:

- core mass flow following pump trip is given by:

$$
w(t)=\frac{1}{1+\frac{t}{t c s t}}
$$

where $w(t)$ is the ratio of mass flow at time t to the initial flow at nominal $100 \%$ operation, and the parameter tcst is the pump coastdown time constant obtained from the pump rotating inertia and the primary system flow resistance.

- the transient response of the reactor power following pump trip is obtained from a point-kinetics evaluation using a single group of delayed neutrons.

- safety boration is simulated by introduction of a -25 $\mathrm{pcm} / \mathrm{s}$ negative reactivity ramp starting at $t=15 \mathrm{~s}$.

- fuel temperature feedback is represented by a linear power defect value between zero and $100 \%$ power, with a single order time delay equal to tf seconds corresponding to the thermal inertia of the fuel rods.

- moderator density feedback is equal to the product of the moderator density coefficient $\alpha_{\mathrm{m}}$ and the change in average moderator density. Moderator density change is calculated from the power-to-flow ratio (equal to coolant enthalpy increase along core height), and coolant enthalpy and specific volume characteristics at 110 bar. Core operating pressure and core inlet temperature are assumed constant over the initial $30 \mathrm{~s}$ duration considered in this calculation.

With these simplifying assumptions the evolution of core power in the considered $30 \mathrm{~s}$ time frame is obtained from the following three coupled differential equations:

$$
\begin{gathered}
\frac{d}{\mathrm{~d} t} q(t)=\frac{1}{\Lambda} *[(d k t o t(q(t), t)-\beta) * q(t)+\beta * c(t)] \\
\frac{d}{\mathrm{~d} t} c(t)=\lambda *[q(t)-c(t)] \\
\frac{d}{\mathrm{~d} t} d k f u(t)=\frac{1}{t f} *[p d *(q(t)-1)-d k f u(t)]
\end{gathered}
$$

and with :

$\mathrm{q}(\mathrm{t})$ is the relative reactor power, that is, reactor power at time $t$ divided by the steady state nominal $100 \%$ power value,

$\mathrm{c}(\mathrm{t})$ is the relative value of the concentration of delayed neutrons, that is, concentration at time $t$ divided by its value at steady state normal operation

$\mathrm{dkfu}(\mathrm{t})$ is the reactivity insertion due to a decrease in fuel temperature which accompanies a decrease in reactor power

$\operatorname{dkmo}(z(t))$ is the change in moderator density contribution to total core reactivity

$\mathrm{dkbo}(\mathrm{t})$ is the negative reactivity insertion due to startup of safety boration after time $t=15 \mathrm{~s}$.

$\operatorname{dktot}(\mathrm{q}(\mathrm{t}), \mathrm{t})$ is the total reactivity value, equal to the sum of dkmo $(\mathrm{z}(\mathrm{t})), \mathrm{dkfu}(\mathrm{t})$, and $\mathrm{dkbo}(\mathrm{t})$

$\mathrm{z}(\mathrm{t})$ is the power to flow ratio,

$$
z(t)=\frac{q(t)}{w(t)}
$$

$\mathrm{w}(\mathrm{t})$ is the relative mass flow rate introduced above, $w(t)=\frac{1}{1+\frac{t}{t c s t}}$

The initial conditions at time $t=0$ are:

$$
q(0)=1 \quad c(0)=1 \quad d k f u(0)=0 .
$$

The three reactivity terms are determined as follows $\mathrm{dkfu}(\mathrm{t})$ is obtained from equation (B4)

$\mathrm{dkbo}(\mathrm{t})$ is given by:

$$
d k b o(t)=-25 \times(t-15) \times \Phi(t-15) \mathrm{pcm}
$$

where $\Phi(t)$ is the unit step function

$\operatorname{dkmo}(\mathrm{z})$ is the product of the moderator density coefficient of reactivity, $\alpha_{\mathrm{m}}$ and the change $\Delta \operatorname{rav}(\mathrm{z})$ in average moderator density in the core, which is:

$$
\operatorname{rav}(z)=\operatorname{rin} \times x l(z)+\operatorname{rsat}+\operatorname{rout}(z) \times(1-x l(z))
$$


rin and $\operatorname{rout}(\mathrm{z})$ are the densities at core inlet and outlet, rsat is the density of saturated liquid at $110 \mathrm{bar}$, and $x l(z)$ is the part of total core enthalpy rise which occurs below saturation temperature. The moderator density contribution to reactivity can be expressed as:

$$
\begin{aligned}
\operatorname{dkmo}(z)= & \alpha_{m} \times \Delta \operatorname{rav}(z)=\frac{\alpha_{m}}{2} \\
& \times\left[\frac{C 1}{z}+\frac{C 2}{K 1+z} \times\left(1-\frac{K 0}{z}\right)-C 3\right]
\end{aligned}
$$

where the constants $\mathrm{C} 1, \mathrm{C} 2, \mathrm{C} 3, \mathrm{~K} 0$, and $\mathrm{K} 1$ are obtained from enthalpy and density properties at core inlet and at the saturation temperature of 110 bar.

The various parameters in equations (B1)-(B9) are the following:

\begin{tabular}{ll}
\hline Pump coastdown time constant & tsct $=14.5 \mathrm{~s}$ \\
\hline Prompt neutron lifetime & $\Lambda=10^{-5} \mathrm{~s}$ \\
$\begin{array}{l}\text { Delayed neutron fraction } \\
\text { Delayed neutron decay constant } \\
\text { Thermal time delay }\end{array}$ & $\begin{array}{l}\lambda=0.0065 \\
\text { constant of the fuel rods }\end{array}$ \\
$\begin{array}{l}\text { Power defect between } 0 \% \\
\text { and 100\% power }\end{array}$ & $\mathrm{pd}=-0.07 \mathrm{~s}^{-1}$ \\
$\begin{array}{l}\text { Moderator density coefficient } \\
\text { Constants included in }\end{array}$ & $\alpha_{\mathrm{m}}=6 \mathrm{pcm} \cdot \mathrm{m}^{3} \cdot \mathrm{kg}^{-1}$ \\
equation (B9) & $\mathrm{C} 1=663.1 \mathrm{~kg} / \mathrm{m}^{3}$ \\
& $\mathrm{C} 2=577.4 \mathrm{~kg} / \mathrm{m}^{3}$ \\
& $\mathrm{C} 3=716.2 \mathrm{~kg} / \mathrm{m}^{3}$ \\
& $\mathrm{~K} 0=0.913$ \\
& $\mathrm{~K} 1=-0.053$ \\
\hline
\end{tabular}

Integration of the differential equations (B2)-(B4) for an initial interval of $30 \mathrm{~s}$ provides the results depicted in Figures B1-B3.

Care must be taken in the interpretation of the results shown in Figures B1-B3, since the impact of the simplifying assumptions used in establishing equations (B2)-(B4) needs to be kept in mind.

Considering in particular the last of these five assumptions (i.e. the constant core pressure and inlet temperature), one can remark that a reactor trip will normally be followed within $5 \mathrm{~s}$ by a turbine trip and concomitant isolation of main steam flow. After main steam flow isolation the steam generator pressure and temperature will increase up to the turbine bypass flow opening pressure or to the SG atmospheric relief valve pressure. As a result the core inlet temperature will tend to increase, with some delay due to thermal inertia in the SG's and the RCS. This introduces an additional negative reactivity, thereby assisting the power reduction towards hot shutdown. Assuming a constant inlet temperature is therefore a conservative approximation for the reactor trip scenario.

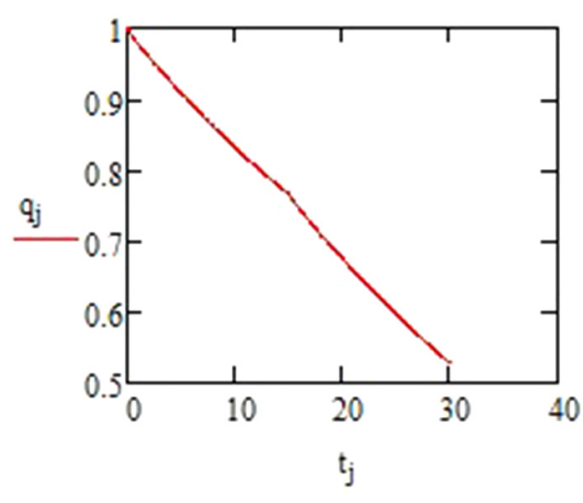

Fig. B1. Relative power vs. time.

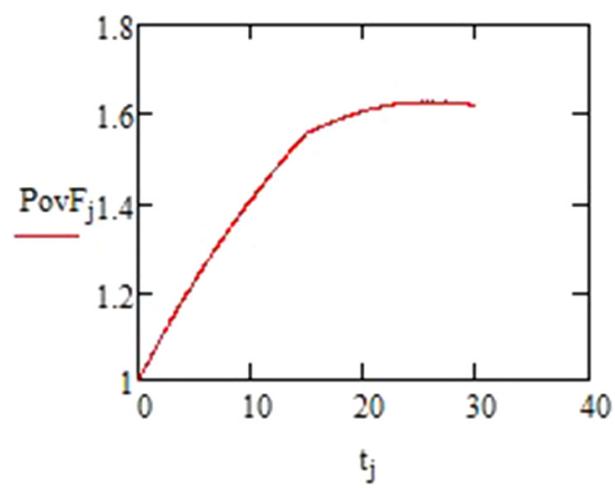

Fig. B2. Power-to-Flow ratio vs. time.

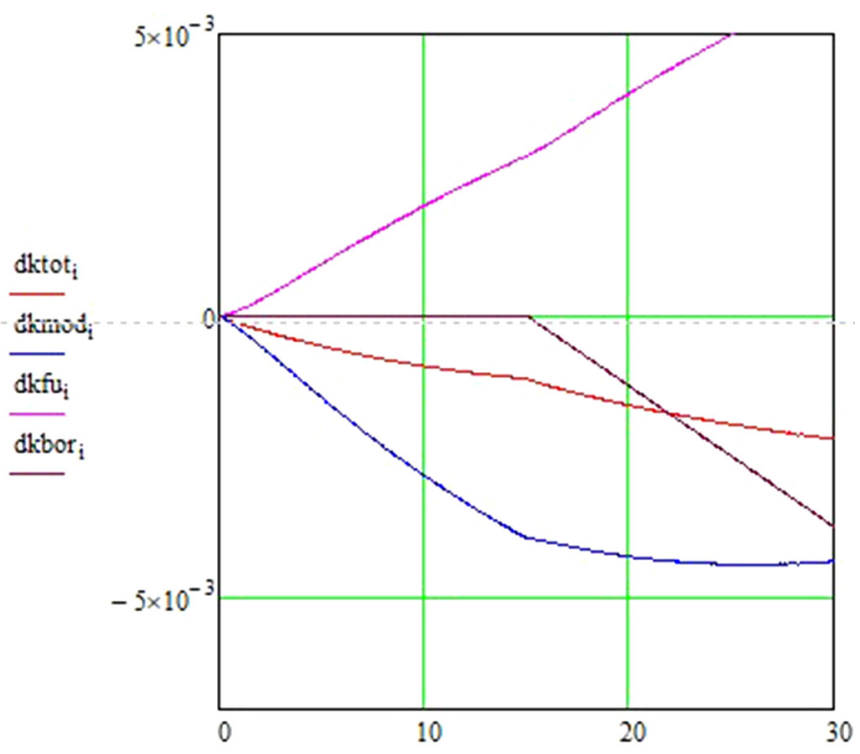

Fig. B3. Reactivity contributions from moderator density, dkmod, fuel, dkfu, and boration, dkbor, together with total reactivity dktot. 
The principal lesson from the results of the simplified model simulation is shown in the evolution of reactivity contributions illustrated in Figure B3. It is apparent that even with a relatively modest moderator density coefficient of $6 \mathrm{pcm} . \mathrm{m}^{3} / \mathrm{kg}$ the reactivity effect of increased upper core voiding will suffice to initiate core power reduction until the time where safety boration is fully operational.

In the case of the PWR design in the PIUS proposal, with the fast safety boration through the "density locks", the lowest acceptable limit on moderator reactivity coefficient is given as $-36 \mathrm{pcm} /{ }^{\circ} \mathrm{C}$ in reference [13]. For the moderator temperature and pressure in PIUS this corresponds to a little more than $10 \mathrm{pcm} . \mathrm{m}^{3} / \mathrm{kg}$. In the selfpressurized PWR the combination of saturated conditions at core outlet, pump trip, and safety boration with redundant trains of pumped safety boration supply will be sufficient even with lower values of moderator density feedback.

\section{References}

1. IEA/NEA (2015) Technology Roadmap: Nuclear Energy. Paris. https://www.oecd-nea.org/pub/techroad map/techroadmap-2015.pdf

2. UNFCCC Secretariat, Aggregate effect of the intended nationally determined contributions: an update (2016), https://doi.org/10.1093/iclqaj/24.3.577

3. IAEA (2018) Advances in Small Modular Reactor Technology Developments 2018 Edition. https://aris.iaea.org/Publi cations/SMR-Book 2018.pdf

4. B. Petrovic, The integral inherently safe light water reactor, Nucl. Eng. Int. (2014), http://www.neimagazine.com/fea tures/featurethe-integral-inherently-safe-light-water-reac tor- $4253617 /$

5. B. Petrovic, F. Rahnema, C. Deo, S. Garimella, P. Singh, K. Oh, C. Yi, D. Zhang, A. Manera, J. Lee, T. Downar, A. Ward, P. Ferroni, F. Franceschini, D. Salazar, B. Upadhyaya, M. Lish, I. Charit, A. Haghighat, M. Memmott, G. Boy, A. Ougouag, G. Parks, D. Kotlyar, M. Ricotti, C. Nikola, D. Grgi, D. Pevec, M. Matijevi, N. Irvin, I2S-LWR concept update, in Proceedings of The 20th Pacific Basin Nuclear Conference, edited by $\mathrm{H}$. Jiang (China Nuclear Power Engineering Co, Ltd, Beijing), (Springer, Singapore, 2016), pp. $153-167$

6. M.S. Ali, Evolution of the leak-before- break concept in nuclear plants: issues and resolutions in the process of regulatory actions, Nucl. Technol. 176, 442-451 (2011)

7. R. Bourga, P. Moore, Y.-J. Janin, B. Wang, J. Sharples, Leak-before-break: global perspectives and procedures, Int. J. Press. Vessel. Pip. 129, 43-49 (2015)

8. P. Scott, R.J. Olson, G.M. Wilkowski, NUREG/CR-6765 Development of Technical Basis for Leak-Before-Break
Evaluation Procedures (2002), Office of Nuclear Regulatory Research, USNRC, Washington DC, 20555-0001, https:// www.nrc.gov/docs/ML0217/ML021720594.pdf

9. T. Deighton, Liquid Moderated Nuclear Reactor. US $3,356,583$ (1967)

10. H. Neumann, Vom Forschungsreaktor zum $\gg$ Atomschiff «OTTO HAHN, 1st edn. ed. (Verlag H.M. Hauschild, Bremen, Germany, 2009)

11. J. Reinartz, Historie Als die Kernenergie "Ahoi" rief. NS Otto Hahn: Nuklearbetriebenes Forschungs-und Frachtschiff. atw Int. J. Nucl. Power 58, 652-656 (2013)

12. IAEA, Stress Corrosion Cracking in Light Water Reactors: Good Practices and Lessons Learned, IAEA Nuclear Energy Series No. NP-T-3.13 (Vienna, 2011)

13. D.C. Groeneveld, L.K.H. Leung, P.L. Kirillov, V.P. Bobkov, I.P. Smogalev, V.N. Vinogradov, X.C. Huang, E. Royer, The 1995 look-up table for critical heat flux in tubes, Nucl. Eng. Des. 163, 1-23 (1996)

14. B. Majborn, K. Brodersen, CF. Højerup, F. Heikel Vinther, editors, Ris $\varnothing$ National Laboratory Nuclear Safety Research Department Annual Progress Report 1992, Ris $\varnothing-\mathrm{R}-679(\mathrm{EN})$ §3. 2. 6, p. 18, 1993

15. K. Hannerz, L. Nillson, T. Pedersen, C. Pind, The PIUS pressurized water reactor: aspects of plant operation and availability, Nucl. Technol. 91, 81-88 (1990)

16. J.M. Taylor, SECY-93-092-Issues pertaining to the advanced reactor (PRISM, MHTGR, and PIUS) and CANDU 3 designs and their relationship to current regulatory requirements (1993), https://www.nrc.gov/docs/ML0402/ML040210725. pdf

17. F.W. Kleimola, Passive containment system for a nuclear reactor. US 3,984,282 (1976)

18. N.M. Bonhomme, Containment for a water cooled and moderated nuclear reactor. US 9,502,142 (2016)

19. G. Cénérino, Accidents graves des réacteurs à eau de production d'électricité, Rapport IRSN-2008/98-FR (2008)

20. IAEA, Severe Accident Management Programmes for Nuclear Power Plants. Safety Guide No. NS-G-2.15, Safety Guide No. NS-G-2.15 (2009), https://www-pub.iaea.org/ MTCD/publications/PDF/Pub1376_web.pdf

21. USNRC, Standard review plan 19.0, NUREG-0800 (2015)

22. H. Esmaili, M. Khatib-Rahbar, NUREG/CR-6849, ERI/ NRC 046201. Analysis of In-Vessel Retention and Ex-Vessel Fuel Coolant Interaction for AP1000 (2004), https://www. nrc.gov/docs/ML0424/ML042460184.pdf

23. IRSN, Eléménts de réfléxion sur la stratégié de réténtion d'un corium en cuve de réactéur (2015), https://www.irsn.fr/FR/ connaissances/Installations_nucleaires/Les-centrales-nucle aires/Documents/IRSN_Reflexion-Strategie-Retention-Co rium-Cuve_V2-07-2015.pdf

24. T.G. Theofanous, C. Liu, S. Additon, S. Angelini, O. Kymäläinen, T. Salmassi, In-vessel coolability and retention of a core melt, DOE/ID-10460, VOLUME 1 (October 1996), https://inis.iaea.org/collection/NCLCollec tionStore/_Public/29/006/29006120.pdf

Cite this article as: Nicolaas M. Bonhomme, A new direction in PWR simplification, EPJ Nuclear Sci. Technol. 7, 2 (2021) 